\title{
Seasonal to yearly assessment of temperature and precipitation trends in the North Western Mediterranean Basin by dynamical downscaling of climate scenarios at high resolution (1971-2050)
}

\author{
M. Gonçalves • A. Barrera-Escoda • D. Guerreiro • \\ J. M. Baldasano $•$ J. Cunillera
}

Received: 4 January 2013 / Accepted: 24 October 2013 / Published online: 19 November 2013

(C) Springer Science+Business Media Dordrecht 2013

\begin{abstract}
The complex topography and high climatic variability of the North Western Mediterranean Basin (NWMB) require a detailed assessment of climate change projections at high resolution. ECHAM5/MPIOM global climate projections for mid-21st century and three different emission scenarios are downscaled at $10 \mathrm{~km}$ resolution over the NWMB, using the WRF-ARW regional model. High resolution improves the spatial distribution of temperature and precipitation climatologies, with Pearson's correlation against observation being higher for WRF-ARW (0.98 for temperature and 0.81 for precipitation) when compared to the ERA40 reanalysis $(0.69$ and 0.53 , respectively). However, downscaled results slightly underestimate mean temperature $(\approx 1.3 \mathrm{~K})$ and overestimate the precipitation field $(\approx 400 \mathrm{~mm} /$ year$)$. Temperature is expected to raise in the NWMB in all considered scenarios (up to $1.4 \mathrm{~K}$ for the annual mean), and particularly during summertime and at high altitude areas. Annual mean precipitation is likely to decrease (around $-5 \%$ to $-13 \%$ for the most extreme scenarios). The climate signal for seasonal precipitation is not so clear, as it is highly influenced by the driving GCM simulation. All scenarios suggest statistically significant decreases of precipitation for mountain ranges in winter and autumn. High resolution simulations of regional climate are potentially useful to decision makers. Nevertheless, uncertainties related to seasonal precipitation projections still persist and have to be addressed.
\end{abstract}

Electronic supplementary material The online version of this article (doi:10.1007/s10584-013-0994-y) contains supplementary material, which is available to authorized users.

M. Gonçalves $(\bowtie) \cdot$ D. Guerreiro • J. M. Baldasano

Earth Sciences Department, Barcelona Supercomputing Center, Barcelona, Spain

e-mail: maria.goncalves@upc.edu

M. Gonçalves • J. M. Baldasano

Projects Department, Technical University of Catalonia, Barcelona, Spain

A. Barrera-Escoda $\cdot$ J. Cunillera

Climate Change Unit, Meteorological Service of Catalonia, Barcelona, Spain 


\section{Introduction}

Mediterranean region is particularly vulnerable to climate change (Giorgi 2006). Global projections suggest changes in temperature and precipitation which would yield drier conditions and increased drought risk in the area (Christensen et al. 2007a).

General Circulation Models (GCMs) resolution leaves several local-to-regional key features unsolved, i.e. orographic derived rain or convective phenomena, which are commonly parameterized or not resolved adequately (Rummukainen 2010). Downscaling techniques have being applied since the early 1990s to provide detailed results over vulnerable or complex regions (Giorgi and Mearns 1991). Among them, dynamical downscaling approaches rely on limitedarea models, based on the description of the physical processes occurring in the atmosphere, which solve regional climate features and are forced by GCMs or reanalysis data. Projects such as PRUDENCE (Christensen et al. 2007b), ENSEMBLES (van der Linden and Mitchell 2009), or more recently CORDEX (http://cordex.dmi.dk/joomla), have developed and improved dynamical downscaling techniques, reaching resolutions up to $25 \mathrm{~km}$ (ENSEMBLES). CORDEX project aims to push this resolution further and explore downscaling results at $12.5 \mathrm{~km}$. In the context of the Iberian Peninsula, the ESCENA initiative (Jiménez-Guerrero et al. 2011) uses different Regional Climate Models (RCMs), emission scenarios and a wide range of GCMs to provide climate projections at $25 \mathrm{~km}$.

The North Western Mediterranean Basin (NWMB) is characterized by a complex topography (Fig. 1). In the northern area two mountainous ranges, parallel to the coastline, affect the influence of the Mediterranean Sea on the climatology of the inland region, which is also conditioned by the presence of the Pyrenees (with peaks above 3,000 m) and the Iberian System mountains. The Ebro Valley acts as an important channel for wind flows. Balearic Islands arise around $200 \mathrm{~km}$ far from the continent, in the Mediterranean. As a result, high climatic contrasts occur in neighboring areas (Martín-Vide 1992). Therefore, it is believed that climate modeling studies covering the NWMB could benefit from resolutions higher than
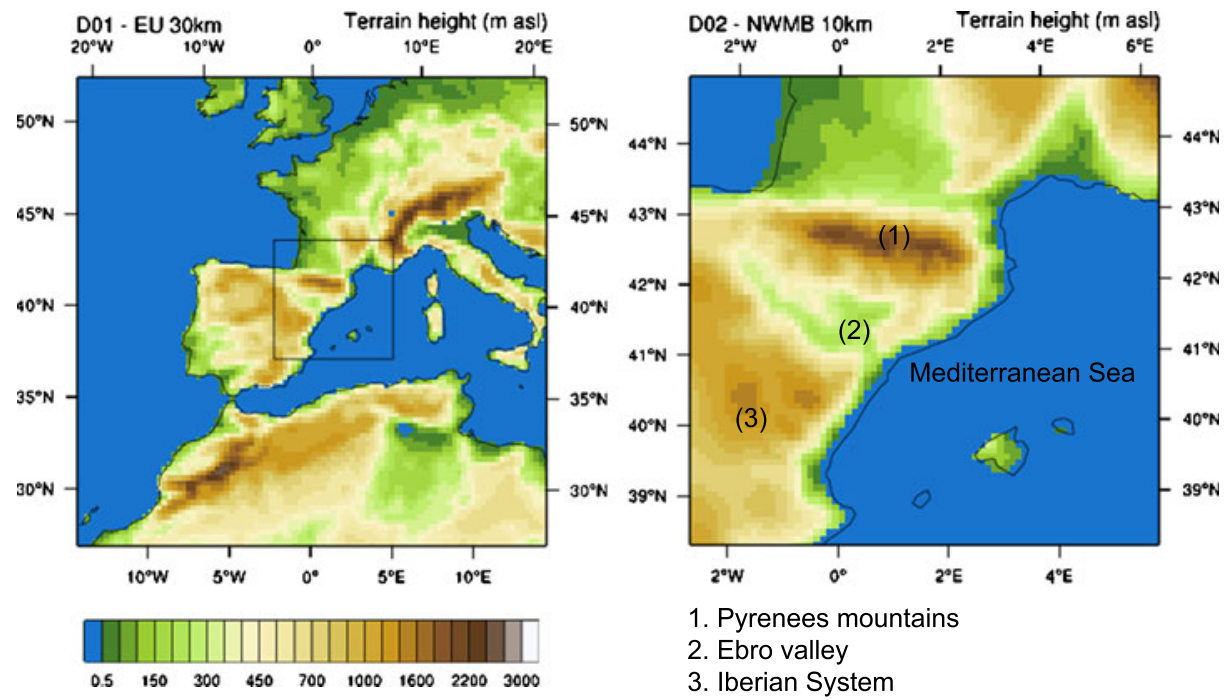

Fig. 1 Domains defined for the WRF-ARW simulations. D01 - left- over Europe and North Africa at $30 \mathrm{~km}$ of horizontal resolution $(100 \times 100$ cells $)$, centered at $41^{\circ} \mathrm{N} 0^{\circ} \mathrm{E}$, and $\mathrm{D} 02$ - right- over the NWMB at $10 \mathrm{~km}$ of horizontal resolution $(76 \times 76$ cells $)$, centered at $41^{\circ} \mathrm{N} 0^{\circ} \mathrm{E}$. Terrain height $(\mathrm{m}$ asl $)$ as represented within WRF-ARW 
$25 \mathrm{~km}$. Increasing horizontal resolution has been proved positive, particularly in complex regions characterized by large interannual and spatial variability in precipitation amounts (Heikkilä et al. 2010; Argüeso et al. 2012a; Cardoso et al. 2012).

Following this direction, this work derives present time (1971-2000) and future (20012050) surface air temperature and precipitation trends for the NWMB using dynamical downscaling techniques at high resolution, $10 \mathrm{~km}$. Simulations use the Advanced Research Weather Research and Forecasting (WRF-ARW) model version 3.2.1 (Skamarock and Klemp 2008) and include three different emissions scenarios: B1, A1B and A2, from those defined in the IPCC-SRES (Nakićenović et al. 2000). Studies covering such large period, 80 years, at that resolution have no precedent for the NWMB.

\section{Methodology}

\subsection{Modeling system}

WRF-ARW is forced by the simulations of the ECHAM5/MPIOM atmosphere-ocean coupled GCM (Roeckner et al. 2003; Marsland et al. 2003). The ECHAM5/MPIOM constitutes one of the GCMs used in AR4 (Randall et al. 2007) with a better performance over Europe below the known radiative forcing for the 20th century (van Ulden and van Oldenborgh 2006), and particularly in the Western Mediterranean (Nieto and Rodríguez-Puebla 2006). GCM data cover three different emission scenarios from the IPCC-SRES (B1, A1B and A2) with two different initializations (simulation 1 and 3 ).

WRF-ARW model configuration is selected according to previous studies for the area (Jorba et al. 2008; Mercader et al. 2010). Two one-way nested domains are defined over the area of interest (Fig. 1), avoiding discontinuities in the main topographic features. D01 covers partially Europe and North Africa at $30 \mathrm{~km}$ resolution. The inner domain (D02) covers the region of interest at $10 \mathrm{~km}$ resolution. 33 vertical sigma layers are defined up to the top of the atmosphere, at $10 \mathrm{hPa}$, to adequately capture the troposphere-stratosphere transport phenomena. A slight spectral nudging above the PBL for the coarsest domain is applied, as it is believed to improve the representation of large scale flows inside the integration area and to avoid the regional model from developing internal states conflicting with the large scale state (von Storch et al. 2000; Heikkilä et al. 2010; Argüeso et al. 2012a). To assess the confidence of the modeling system a control period over the 20th century is selected (1971-2000) and the WRF-ARW is forced by the ERA40 reanalysis (Uppala et al. 2005). Table 1 summarizes the main characteristics of the 9 simulations performed within this work.

For computational purposes, simulations are split into 5-year periods and a 4-month spin-up is applied to minimize the initial conditions effect. The ECHAM5/MPIOM model does not provide the necessary soil variables to run the Noah LSM, therefore they are initialized using values from ERA40 and assumed to reach the equilibrium state after the spin-up.

\subsection{Observational data and model assessment metrics}

Modeling system validation is a key point to provide a level of confidence on future modeling projections. Gridded observational datasets are usually assumed as the best approaches to reality. However, they present non negligible differences over the same region and these uncertainties have to be considered (Gómez-Navarro et al. 2012). For this work, Spain02 (SP02) is selected (Herrera et al. 2012) due to the high density of the observational network included. SP02 provides daily surface air temperature and accumulated precipitation for Spain 


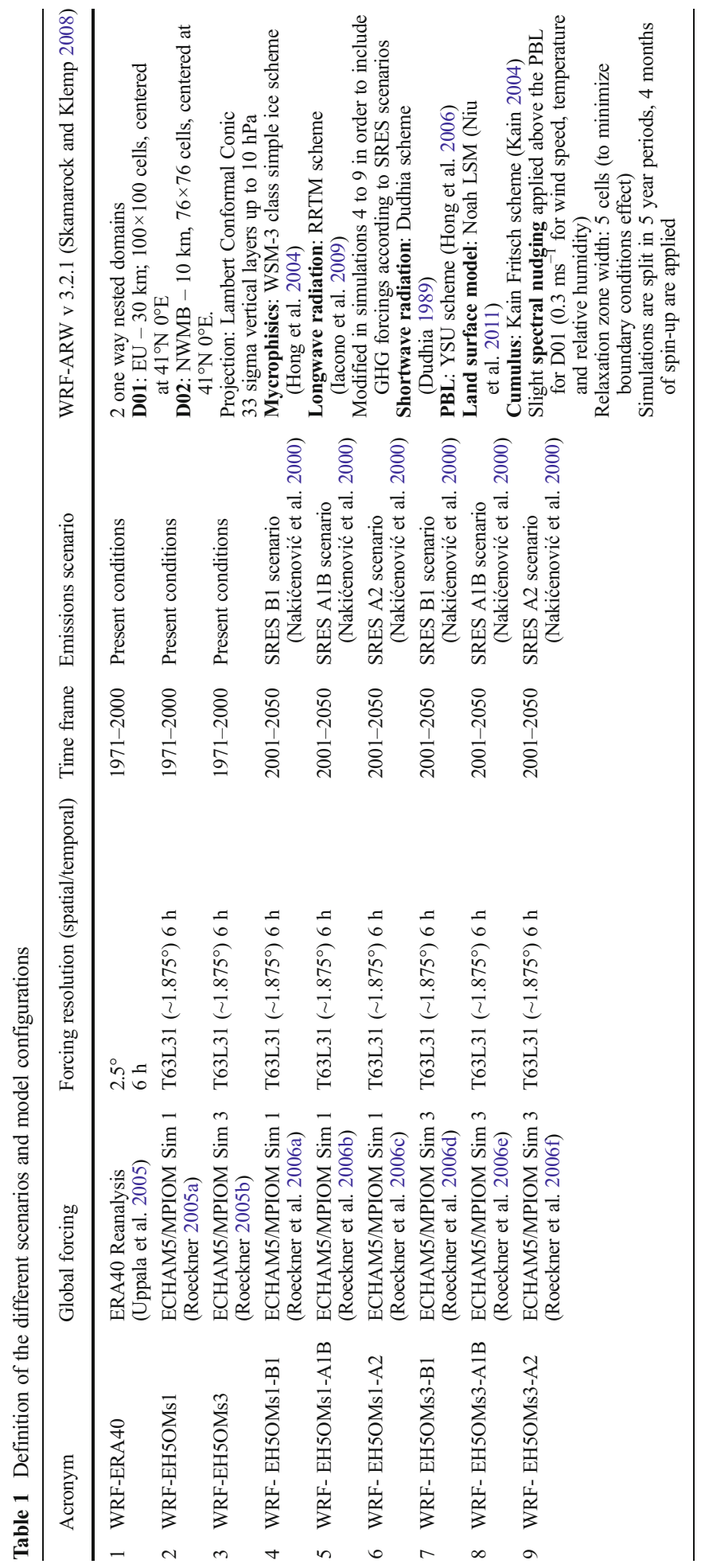


over a regular grid of $0.2^{\circ}$ resolution. The coarser resolution compared to the $10 \mathrm{~km}$ of WRF simulations introduces an additional source of uncertainty, but reliable gridded datasets at more suitable resolutions are not currently available. For spatial comparisons, modeled fields are bilinearly interpolated from the different grids to the $0.2^{\circ} \mathrm{SP} 02$ grid.

Additionally, the model performance at high resolution is assessed against high quality data from 20 meteorological stations (SMC 2012). Model results are bi-linearly interpolated to the stations location. Modeled temperature is corrected with altitude according to the standard lapse rate $(-6.5 \mathrm{~K} / \mathrm{km})$. Although more complex methods have shown improvements in coarser models (Gao et al. 2012), comparison of different techniques at high resolution suggests that further correction is not needed (Soares et al. 2012).

Absolute biases for temperature and relative biases for precipitation allow quantifying model deviations from observations on average for the NWMB and for each grid cell at different temporal scales. Spatial spread and temporal variability are measured through standard deviation $(\sigma)$ for temperature and the coefficient of variation $(\mathrm{CV})$ for precipitation. Temporal matching between model and observations is measured through the Pearson's correlation coefficient (r). Data are previously normalized by its corresponding seasonal or monthly mean and $\sigma$ for the control period (to remove the autocorrelation due to intra-annual variability). A Fisher's z transformation of correlation coefficients together with a two-tailed Student's $t$-test provides the statistical significance of the correlations. Temporal trends are derived from a linear regression and its statistical significance is calculated by a Monte Carlo technique at a $95 \%$ confidence level (Livezey and Chen 1983). Monthly mean temperature (MMT) and precipitation (MMP) probability density functions (PDFs) are also estimated. A quantitative assessment of the matching between modelled and observed PDFs is provided via a Kolmogorov-Smirnov (KS) test (Wilks 2006).

Model skills to reproduce observed spatial patterns of temperature and precipitation are assessed by estimating normalized root mean square error (NRMSE), correlation and normalized $\sigma$. These parameters for different models and model configurations are compared via Taylor diagrams (Taylor 2001).

\subsection{Temperature patterns and variability assessment}

Observed Annual Mean Temperature Climatology -AMTC- (1971-2000) for the NWMB (Online Resource 1) peaks along the coast line and the Ebro Valley (292.5 K). Minimum temperatures occur in mountain ranges, the Pyrenees and the Iberian System (275.0 K).

WRF-ERA40 tends to underestimate the surface air temperature (on average $-1.3 \mathrm{~K}$, Online Resource 2). For some areas, i.e. the southern Mediterranean coast or specific spots in the Pyrenees, biases can be larger (around $-2.5 \mathrm{~K}$ ). WRF-ERA40 PDF for MMT also reflects the cold bias, showing a probability displacement towards lower values than observations. Nonetheless, WRF-ERA40 and SP02 PDFs are statistically consistent at a $99 \%$ confidence level, whereas ERA40 and SP02 PDFs are statistically independent, as derived from a KS test (Online Resource 3).

WRF-ERA40 reproduces the geographical pattern of AMTC outstandingly $(r=0.97)$ and biases are overall improved from coarser resolutions (Online Resource 1). Figure 2 compares the spatial performance of 17 RCMs included in ENSEMBLES (van der Linden and Mitchell 2009), WRF-ERA40 simulations at 30 and $10 \mathrm{~km}$ and the ERA40 reanalysis against SP02. RCMs show good skills in reproducing the AMTC patterns: being spatial correlation above 0.9 for a majority of models, NRMSE below 0.4 and $\sigma$ close to the observed value (1.0), clearly improving the coarse reanalysis performance. The gain is smaller from 30 to $10 \mathrm{~km}$ resolution, but the refinement still has an effect on AMTC patterns (Fig. 2a). Moreover, 10-km 

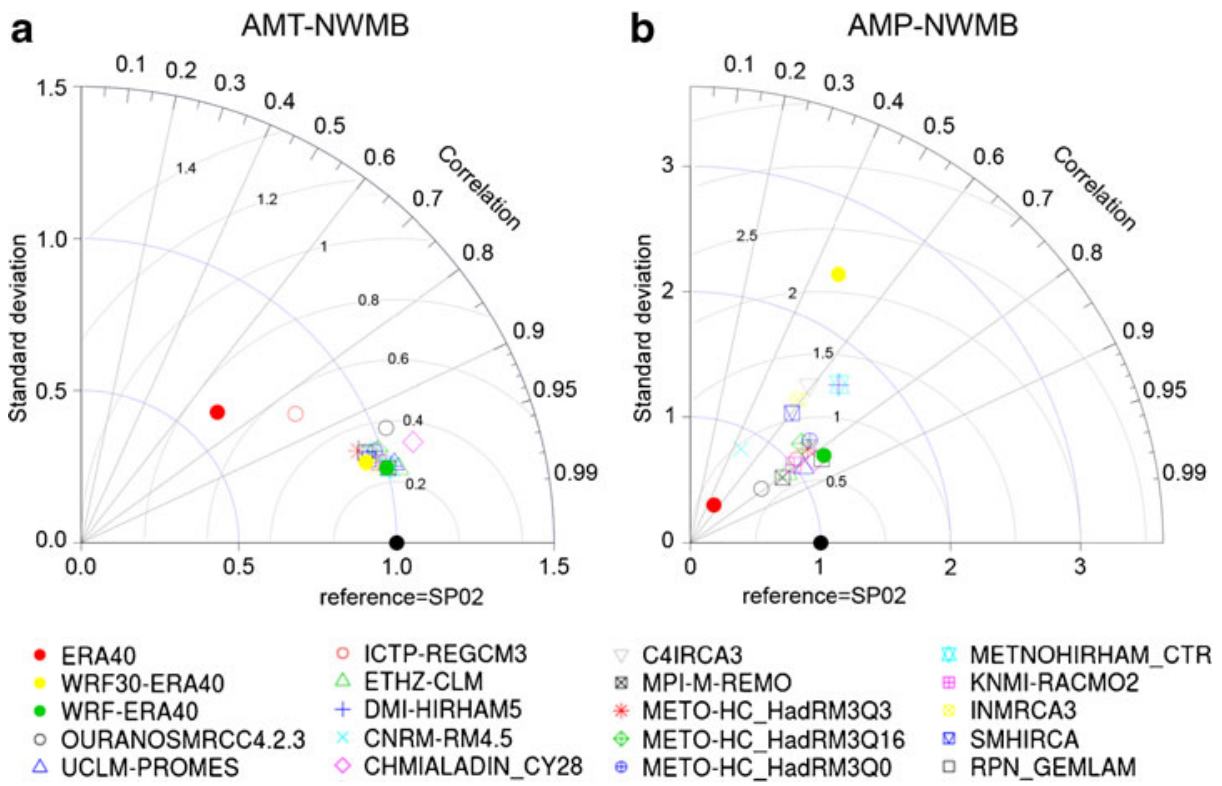

Fig. 2 Taylor diagram comparing AMTC (a) and AMPC (b) for different ENSEMBLES models $(\approx 25 \mathrm{~km}$ resolution), WRF-ERA40 at $10 \mathrm{~km}$ (WRF-ERA40) and $30 \mathrm{~km}$ (WRF30-ERA40) and ERA40 reanalysis vs the SP02 observations database $\left(0.2^{\circ} \approx 20 \mathrm{~km}\right.$ resolution) for 1971-2000. Spatial Pearson's correlation is shown in the radial axis, standard deviation $(\sigma)$ in the xy axis and Root Mean Square Error (RMSE) in the arcs within the panel. RMSE and $\sigma$ for all models are normalized dividing them by the $\sigma$ of observations. SP02 reference conditions are represented by a black dot in the $\mathrm{x}$ axis ( 1.0 for $\sigma$ and correlation and 0.0 for RMSE)

WRF-ERA40 compared to meteorological stations series presents maximum biases for AMTC up to $-2.5 \mathrm{~K}$ (Online Resource 1). Inter and intra-annual variability of temperature are also well captured at local scale, showing high temporal correlations for the annual (monthly) means, $\mathrm{r}$ above $0.7(0.8)$ respect to stations data (Online Resource 1).

The NWMB is characterized by a Mediterranean climate, warmer in summer, particularly in inland flat areas and in the coast. Minimum temperatures are registered in wintertime, especially over the highest mountain ranges. WRF-ERA40 correctly reproduces the temperature variability along the year, presenting a cold bias for all seasons, which is larger in summertime, up to $-2.5 \mathrm{~K}$ on average. Differences are amplified by WRF-ERA40 respect to the reanalysis itself, however seasonal temperature spread $(\sigma)$ is comparable to SP02 and ERA40 values. Seasonal correlations are above 0.9 , except for wintertime $(r=0.87$, Online Resource 2).

\subsection{Precipitation patterns and variability assessment}

Observed Annual Mean Precipitation Climatology (AMPC) for 1971-2000 over the NWMB peaks at the highest mountain areas (above 1,400 mm/year). Some coastal areas are also characterized by large precipitation amounts, above $800 \mathrm{~mm} /$ year. The flat inland region constitutes the driest area, with AMPC around $400 \mathrm{~mm} /$ year (Fig. 3a and e).

WRF-ERA40 enhances the precipitation field respect to ERA40 reanalysis (Fig. $3 \mathrm{~b}$ to d), which results in an overestimation of AMPC compared to SP02. Relative biases are generally below $30 \%$, but peak at the Pyrenees (deviations up to $120 \%$ ). The assessment against meteorological stations data suggests local underestimations of precipitation along the coast 

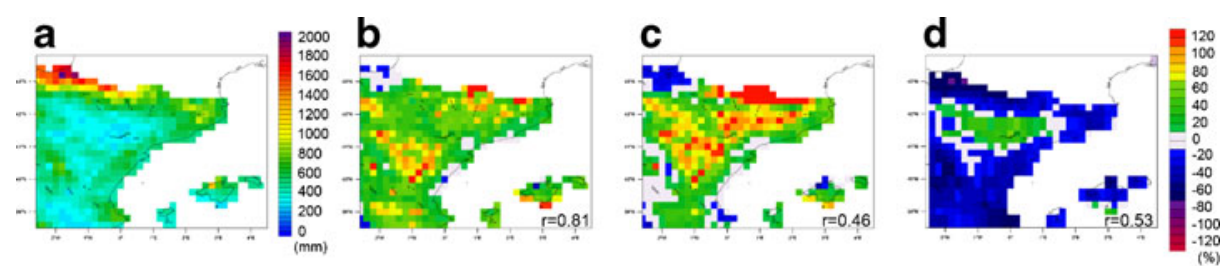

e
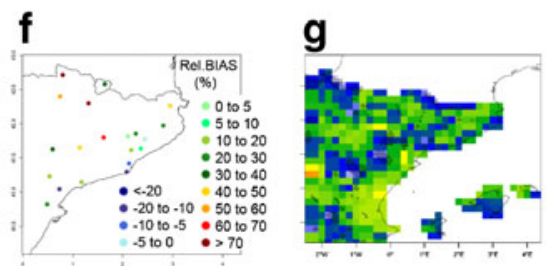

h
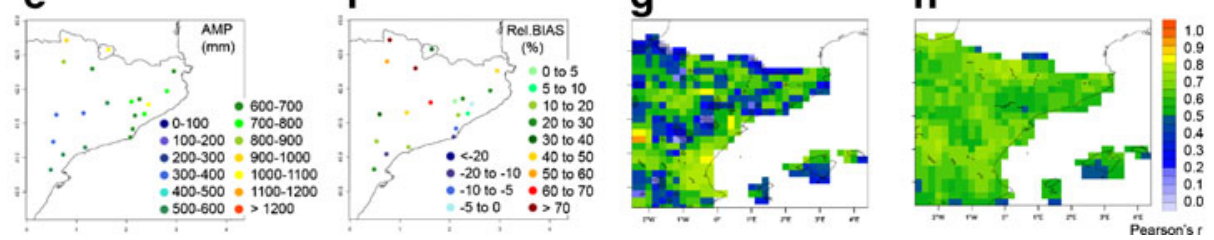

Fig. 3 a AMPC (1971-2000) in mm for the NWMB based on SP02 observations. Relative bias of AMPC (\%) between b WRF-ERA40 at $10 \mathrm{~km}$, c WRF-ERA40 at $30 \mathrm{~km}$, d ERA40 and SP02. Values for r correspond to the spatial correlation between model and observations. e AMPC (1971-2000) in mm as derived from meteorological stations data. f Relative bias of AMPC (\%) between WRF-ERA40 at $10 \mathrm{~km}$ and meteorological stations data. Temporal Pearson's correlation for WRF-ERA40 versus SP02 in an $\mathbf{g}$ annual and $\mathbf{h}$ monthly basis. Shaded areas represent non statistically significant correlations at a $95 \%$ confidence level

and confirms the overestimation for the mountains, particularly the western Pyrenees (Fig. 3f). Also, MMP PDFs show a probability displacement towards higher values for WRF-ERA40 compared to SP02. Consequently, both PDFs are statistically independent at a $99 \%$ confidence level, assessed through a KS test. Anyway, WRF-ERA40 has a better performance than ERA40 with a PDF statistically closer to SP02 than ERA40 (The KS statistic computed for WRF-ERA, $d=0.26$, and for ERA40, $d=0.39$ ).

Despite these deviations, the high resolution simulations correctly reproduce the spatial precipitation patterns, $\mathrm{r}$ above 0.8 for all cases, improving the ERA40 reanalysis and the $30-\mathrm{km}$ WRF-ERA40 (both showing $\mathrm{r} \approx 0.5$ ). 10 -km WRF-ERA40 correlation is on the same order of magnitude than the best performing models from ENSEMBLES, i.e. KNMI-RACMO2, UCLM-PROMES or ETHZ-CLM (Fig. 2b). However, 10-km WRF-ERA40 AMPC projections present lower accuracy (NRMSE $\approx 0.75$ ) respect to some models in ENSEMBLES $(\mathrm{NRMSE} \approx 0.60$, for UCML-PROMES and MPI-M-REMO) and its spatial variability is slightly larger (normalized $\sigma$ is 1.3 for 10-km WRF-ERA40 vs. 0.98 for KNMI-RACMO2). The spread and correlation improve when increasing the resolution from ERA40, but accuracy of RCMs is on the same order of the reanalysis data.

Year-to-year variability for precipitation is well defined by WRF-ERA40 simulations ( $\mathrm{r}$ above 0.5 for large areas of the domain, Fig. $3 \mathrm{~g}$ ). Correlations along the Mediterranean coast and the Iberian System are high, with values above 0.7 and up to 0.9 , which are confirmed by the assessment against meteorological station series (i.e. $r=0.83$ for AMP at coastal stations, Online Resource 4). Previous works highlighted the difficulties of RCMs to reproduce precipitation in the Mediterranean basin (Jiménez-Guerrero et al. 2011), showing correlations around 0.6. WRF-ERA40 lowest annual correlation values are found above the driest areas, characterized by long dry periods and scarce heavy precipitation events (Romero et al. 1998a). Model schemes have difficulties to reproduce these convective processes adequately (Romero et al. 1998b; Martin et al. 2007) even at high resolution (Heikkilä et al. 2010; Cardoso et al. 2012), which could be in the origin of the low temporal correlation and the biases already discussed (Fig. $3 g$ and Online Resource 4). Some mountain areas show also a poor performance (i.e. western Pyrenees, Fig. 3g and Online Resource 4), suggesting that even with the high resolution 


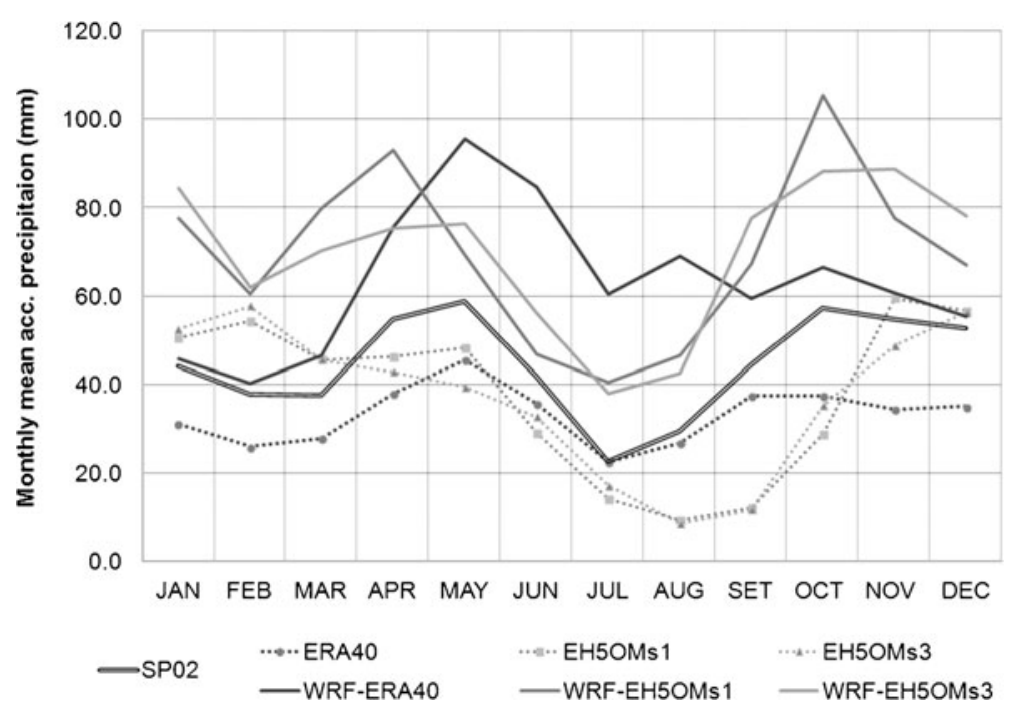

Fig. 4 Annual cycle of precipitation as obtained from SP02 observations, WRF-ERA40, WRF-EH5OMs1, WRF-EH5OMs3, ERA40 reanalysis and the EH5OMs1 and s3 for 1971-2000 on average for the NWMB

used, some features of the orographically enhanced precipitation and processes involved in the hydrological cycle in mountains are not well captured by the model (Beninston 2003).

NWMB precipitation shows a high intra-annual and spatial variability (Fig. 4 and Online Resource 5). Wintertime precipitation peaks at high altitude locations (above $400 \mathrm{~mm}$ ). However, flat inland areas are much drier (below $100 \mathrm{~mm}$ ). Rain is more abundant in those regions in autumn and spring, frequently above $150 \mathrm{~mm}$. The Mediterranean coast is also characterized by values of accumulated precipitation around $150 \mathrm{~mm}$. Summertime constitutes the driest season, with maximum precipitation amounts registered on the Pyrenees below $350 \mathrm{~mm}$.

WRF-ERA40 is able to reproduce the annual precipitation cycle, although it overestimates precipitation for all seasons (Fig. 4 and Online Resource 5). Biases are below $50 \%$ for winter and autumn. The poorest performance is found on summertime. WRF-ERA40 overestimates the convective processes characteristic of this season, which are responsible for up to $80 \%$ of total simulated precipitation. This may be due to the physical parameterizations chosen and to the topography representation within the model (Fig. 1), which has deviations respect to reality. Temporal variability is also poorly captured for summer, showing no statistically significant correlations for the driest areas and along the coast. Seasonal variability is however well represented in winter, spring and autumn, with large areas of the domain showing $\mathrm{r}$ above 0.7 (Online Resource 5).

Global forcing influences the ability of WRF-ARW model to reproduce the seasonal precipitation. WRF-EH5OM simulations show the largest positive biases over the Pyrenees and the Iberian System. Contrarily, seasonal precipitation in coastal areas is underestimated by 10 to $30 \%$ (not shown). Summertime precipitation representation improves when WRF-EH5OM is applied with respect to WRF-ERA40 simulations, owing to its drier behavior (Fig. 4).

Summarizing, WRF-ERA40 shows the lowest deviations from SP02 for wintertime and autumn, it overestimates springtime precipitation and it largely enhances summertime precipitation. The best correlation between modeled and observed annual cycle (Fig. 4) is provided by the WRF-EH5OMs3 simulations (0.9). WRF-ERA40 shows lower correlation values, attributed to difficulties in reproducing the driest months. However, the intra-annual variability 
is relatively well captured for the whole domain. Month-to-month correlation values are above 0.5 (Fig. 3f). When the integrated values for the NWMB are considered (Online Resource 2), WRF-ERA40 shows a precipitation spread closer to SP02 than ERA40 itself. However, temporal correlation values are on the same order of magnitude for ERA40 than for the WRF-ERA40 on the different time scales, except for autumn, when a clear improvement is shown in high resolution results.

\section{Temperature projections for the NWMB}

Annual Mean Temperature (AMT) in the mid-21st century is expected to rise respect to 19712000 mean independently of the emissions scenario considered (Fig. 5a). All scenarios present statistically significant linear trends ranging from $0.4 \mathrm{~K}$ to $1.4 \mathrm{~K}$ in 50 years. AMT variability would be larger in the first half of the 21 st century for the A2 $(\sigma=0.67(0.65) \mathrm{K})$ and A1B $(\sigma=0.76(0.71) \mathrm{K})$ scenarios, respect to $1971-2000(\sigma=0.39(0.59) \mathrm{K})$ according to WRFEH5OMs1 (s3)), particularly from 2030 onwards. Results are consistent with the GCMs projections, but variability is slightly enhanced by the RCM. This amplification is also evidenced by comparing RCMs projected variability for 2001-2008 ( $\sigma$ up to $0.68 \mathrm{~K}$ ) and the observed value $(\sigma=0.37 \mathrm{~K})$.

Geographically, temperature projections are quite consistent among all scenarios (Online Resource 6). AMT would increase in 2021-2050 with respect to the 1971-2000 mean in 0.6 to $2.0 \mathrm{~K}$. There is a latitudinal and altitudinal gradient in temperature variations, being larger at higher altitudes and northern areas. The Pyrenees would be the most affected area, independently of the considered scenario. This is consistent with previous studies showing a dependency of the climate signal with elevation (Giorgi et al. 1997; Beninston 2003). Projected temperature raise for $\mathrm{A} 1 \mathrm{~B}$ and $\mathrm{A} 2$ is similar (up to $2.0 \mathrm{~K}$ ), according to the almost equivalent

a
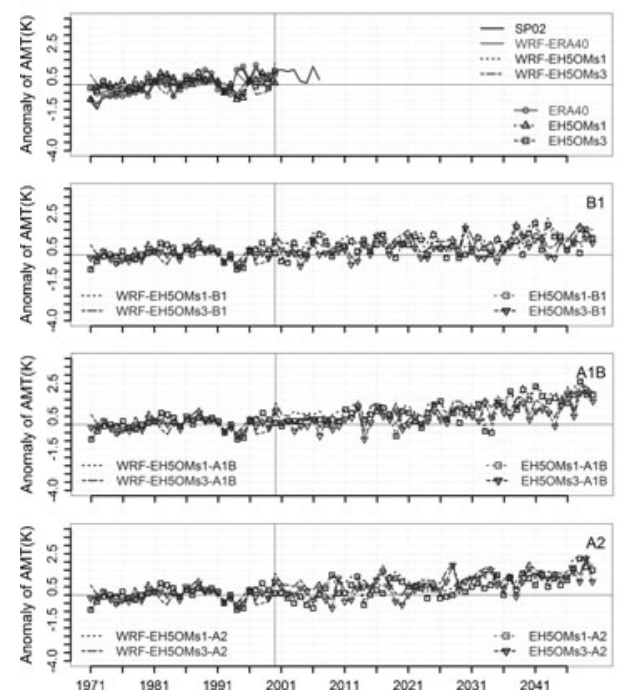

b
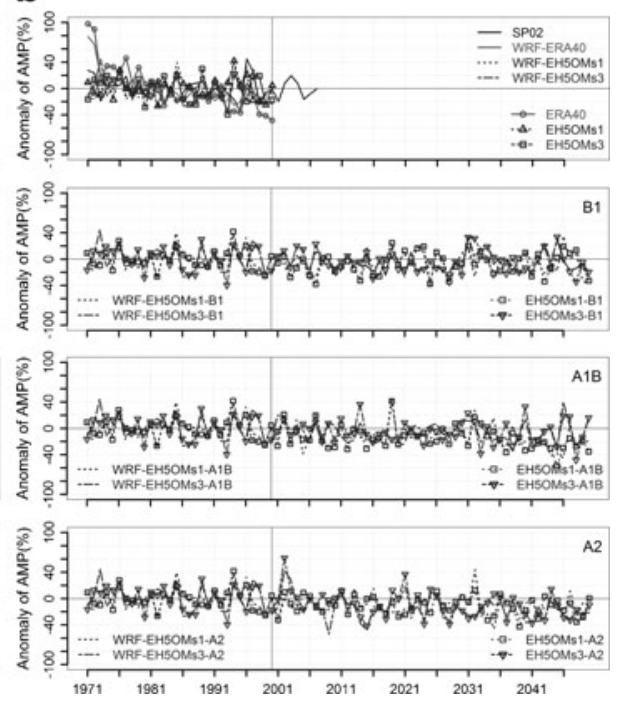

Fig. 5 Anomaly of annual mean a temperature and $\mathbf{b}$ precipitation in the NWMB for 1971-2050 as derived from SP02, WRF-ERA40, WRF-EH5OMs1 and WRF-EH5OMs3, considering 1971-2000 as the reference period in the control period, A2, A1B and B1 scenarios (top to bottom) 
GHG emissions evolution until mid-21st century (Nakićenović et al. 2000). B1, a more optimistic scenario, is associated with lower AMT changes (up to $1.4 \mathrm{~K}$ ). Seasonally, summertime temperature would increase the most (up to $2.0-2.5 \mathrm{~K}$ at the Pyrenees for $\mathrm{A} 1 \mathrm{~B}$ and A2). Projected wintertime changes are lower, but still significant in the northern area (increases up to $1.6 \mathrm{~K}$ ). These results are consistent with previous findings for the region at 15-km resolution (Barrera-Escoda and Cunillera 2011) for A2 and B1 scenarios, and coherent with the ENSEMBLES results (van der Linden and Mitchell 2009) for the A1B scenario.

\section{Precipitation projections for the NWMB}

Inter-annual variability of Annual Mean Precipitation (AMP) is projected to increase until 2050 in all scenarios, except WRF-EH5OMs1-A2 (Fig. 5b), particularly from 2030 on (CV= 17-19 \% for 1971-2000; CV=18-23\% for 2031-2050). However, projections may be enhancing this variability, as it is suggested when comparing WRF-EH5OMs1 and s3 (CV up to $26 \%)$ respect to SP02 $(\mathrm{CV}=14 \%)$ for 2001-2008. Regional projections are highly influenced by boundary conditions, as AMP interannual changes depend not only on the emissions scenario, but also on the EH5OM simulation, following on average the GCM projections.

A1B scenario and WRF-EH5OMs3-A2 present a statistically significant reduction of AMP (up to $-13 \%$ in 50 years), consistent with the climate signal identified in previous works for southern Europe in the A1B scenario (van der Linden and Mitchell 2009). However, WRFEH5OMs1-B1 shows an opposite trend (9.5\% in 50 years). No significant trends are found in WRF-EH5OMs1-A2 and WRF-EH5OMs3-B1.

Geographically, AMP would most certainly decrease from $-10 \%$ to $-25 \%$ in $2021-2050$ with respect to 1971-2000 in the Pyrenees and the Iberian System, independently of the GHG emissions scenario (Fig. 6). Precipitation change in mountains may be related to changes in circulation patterns (Giorgi et al. 1997; Gao et al. 2006). More stable conditions are found for instance in WRF-EH5OMs3-A2 projections of wind field and geopotential height at $850 \mathrm{hPa}$. Inland areas show no statistically significant differences at a $95 \%$ confidence level, as assessed by a two-tailed Student's $t$-test, between 2021-2050 and 1971-2000.

Seasonal precipitation projections are quite uncertain (Online Resource 7). Reductions of precipitation for 2021-2050 respect to 1971-2000 are consistently shown among scenarios for winter and autumn over high mountain ranges. The Pyrenees could be up to $35 \%$ drier, although the geographical extent of the affected area is highly dependent on the scenario. Inland areas could be also drier in spring (up to $-30 \%$ ), but the signal of change is weak (only two of the six different simulations show statistically significant reductions). Summertime projections present non statistically significant changes, except for the north face of the Pyrenees, which could be affected by reductions up to $20 \%$.

Previous works (Barrera-Escoda and Cunillera 2011) projected similar changes for seasonal precipitation in case of B1 and A2 scenarios. Moreover, long term projections (2071-2100) for the A1B scenario seem to confirm these trends. The ENSEMBLES project suggests a decrease of the seasonal precipitation in the NWMB in all seasons except for wintertime, when slight increases are projected inland. Argüeso et al. (2012b) using WRF-ARW at high resolution shows decreases of wintertime precipitation for the western Pyrenees, in agreement with the signals detected in this work. ESCENA (http://proyectoescena.uclm.es/) results for 2021-2050 detect also the largest dispersion in summertime precipitation, together with a high influence of the GCM driving model on RCM projections. 

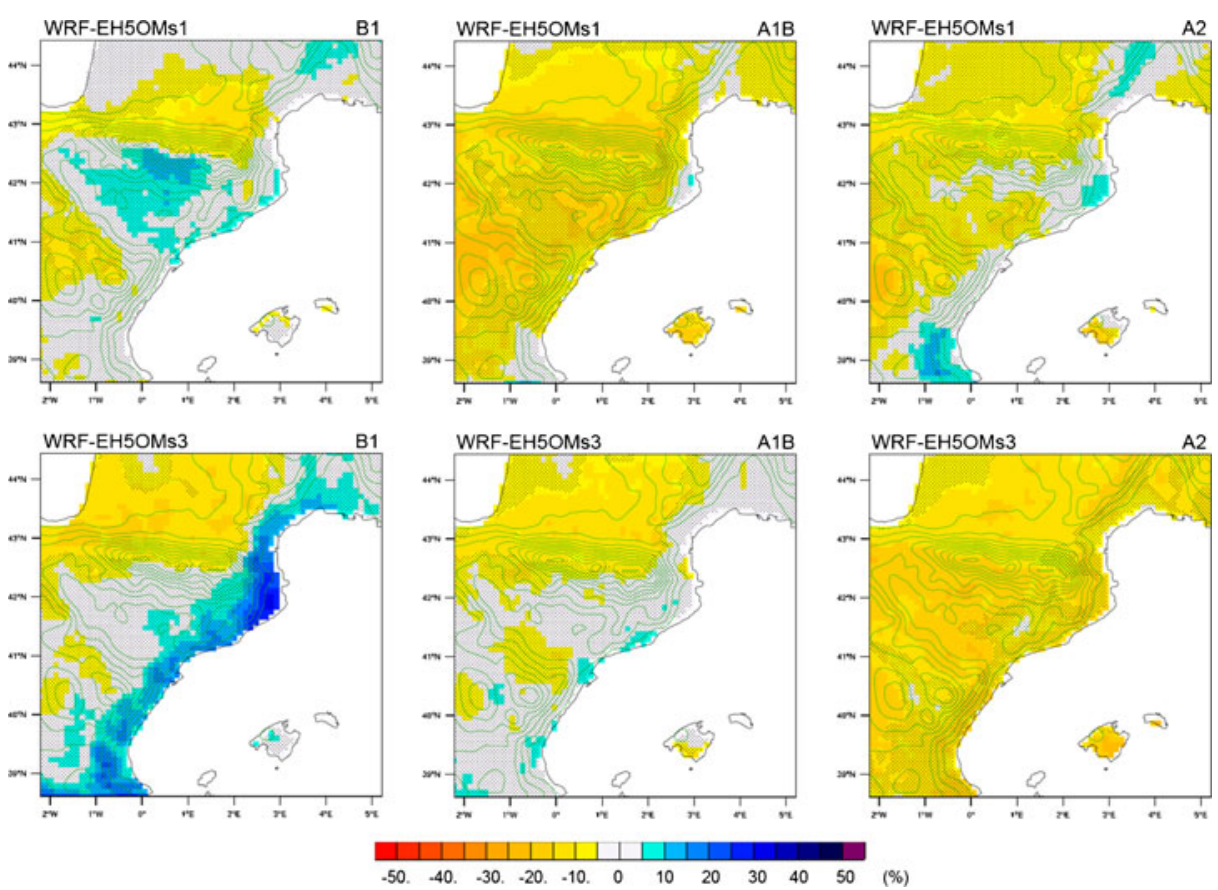

Fig. 6 Differences in annual precipitation (\%) between 2021-2050 and 1971-2000 for the NWMB as projected by WRF-EH5OMs1 (upper panels) and WRF-EH5OMs3 (lower panels) for the B1, A1B and A2 emissions scenarios (from left to right). Shaded areas represent the grid points where the differences are not statistically significant considering a two-tailed Student's $t$-test at a $95 \%$ confidence level. Contour lines represent terrain height every $200 \mathrm{~m}$

\section{Conclusions}

The RCMs used in this study, as well as other commonly used models analyzed, show good skills in reproducing mean temperature patterns, evolution and variability, both in an annual and seasonal basis. However, the ERA40 itself proves equivalent skills for geographically averaged values over the NWMB. The shift from GCMs to RCMs has a clear positive impact on AMTC reproduction, when measured in terms of spatial Pearson's correlation, standard deviation and root mean square error. The improvement in spatial correlation from the increase of horizontal resolution above a certain threshold (30 to $10 \mathrm{~km}$ ) is comparable to this obtained by using different physical parameterizations within the models. The benefits of the increased resolution may be masked because the gridded observational database, SP02, has also a coarser resolution $\left(0.2^{\circ} \approx 20 \mathrm{~km}\right)$ than the WRF-ERA40 model $(10 \mathrm{~km})$. Validation against data from meteorological stations yields low biases (below $2.5 \mathrm{~K}$ in all cases) and a good reproducibility of the inter and intra-annual variability ( $\mathrm{r}$ above 0.7 ).

Mean temperature projections are consistent for a variety of models over the NWMB region. AMT is projected to raise up to $1.4 \mathrm{~K}$ for 2021-2050. Seasonally, summertime temperatures would increase the most, particularly at high altitude areas, being up to $2.5 \mathrm{~K}$ larger than for 1971-2000 at the most intensive emission scenarios.

The spatial definition and spread of AMPC clearly improves in RCMs respect to the raw reanalysis data, and further when increasing resolution from 30 to $10 \mathrm{~km}$. Even in complex terrains, the large scale patterns have an important influence on simulated precipitation, being 
WRF-EH5OM spatial variability larger than WRF-ERA40. Seasonally, WRF-ERA40 highly overestimates precipitation field in summertime, mostly associated with convective processes, probably due to the physical parameterizations applied. Biases of precipitation for winter, autumn and even spring are lower. Year-to-year variability for precipitation is well captured by the simulations on average for the NWMB $(r=0.62)$. Specific areas, like the Mediterranean Coast or the Iberian System, show temporal correlations higher than 0.7. The highest biases and lower correlations are related to dry inland areas, which are usually characterized by long dry periods followed by heavy precipitation events. State-of-the-art mesoscale models still have problems to capture precipitation behavior in such conditions at $10 \mathrm{~km}$ or equivalent resolutions.

AMP projections suggest an enhancement of interannual variability, especially for A1B and A2 scenarios and in coastal areas. Overall, the AMP would most likely decrease in a 5-13\% in the NWMB. However, the signal would be different depending on the specific area. Almost all scenarios suggest a decrease of AMP amount in the Pyrenees and Iberian System, some of them showing also reductions inland, while non statistically significant changes are found along the coast.

Seasonal changes are quite uncertain, as they are highly influenced both by the emissions scenario and the GCM forcing applied. Winter and autumn precipitation would most certainly decrease at high altitude locations (up to $-30 \%$ ). Summertime would be drier in localized areas of the Pyrenees, particularly the north face (up to $-20 \%$ ). Non statistically significant changes are detected for coastal areas.

In summary, increasing the resolution by itself improves the representation of spatial patterns of AMP and yields high year-to-year correlations with observations. But it is still insufficient to solve specific problems related to the reproduction of seasonal precipitation and intra-annual variability. Despite its limitations, climate simulations at high resolution $(10 \mathrm{~km})$ provide an added value for climate analysis, which justifies the computational effort for regions with complex topography and large climate variability. They allow us to provide a better definition of local details of the variation of temperature and precipitation fields which are fundamental for decision makers. They enable to identify particularly vulnerable areas to climate change, as they could be the Pyrenees, where all scenarios consistently project the highest increases in mean temperature and the largest reductions in precipitation. Consequences could be of great concern, as they could affect the load of the main freshwater reservoirs in the area.

It is fundamental to continue improving the projections of regional climate, and to do so not only increasing models resolution or improving physical parameterizations within RCMs, but also increasing the quality and availability of the observational databases for model validation and providing reliable GCM results in order to reduce uncertainties.

Acknowledgments The authors gratefully acknowledge AEMET and UC for the data provided for this work (Spain02 dataset, http://www.meteo.unican.es/datasets/spain02). Data from the RCM used in the ENSEMBLES project have been retrieved from the ENSEMBLES website: http://www.ensembles-eu.org/. We also thank the ECMWF for the ERA40 reanalysis and the World Data Center for Climate in Hamburg for the ECHAM5/MPIOM simulations.

\section{References}

Argüeso D et al (2012a) Evaluation of WRF mean and extreme precipitation over Spain: present climate (19701999). J Clim 25:4883-4897. doi:10.1175/JCLI-D-11-00276.1

Argüeso D et al (2012b) High-resolution projections of mean and extreme precipitation over Spain using the WRF model (2070-2099 versus 1970-1999). J Geophys Res 117, D12108. doi:10.1029/2011JD017399

Barrera-Escoda A, Cunillera J (2011) Climate change projections for Catalonia (NE Iberian Peninsula). Part I: Regional climate modeling. Tethys 8:75-87. doi:10.3369/tethys.2011.8.08 
Beninston M (2003) Climatic change in mountain regions: a review of possible impacts. Clim Chang 59:5-31

Cardoso RM, Soares PMM, Miranda PMA, Belo-Pereira M (2012) WRF high resolution simulation of Iberian Mean and extreme precipitation climate. Int J Climatol. doi:10.1002/joc.3616

Christensen JH et al (2007a) Regional climate projections. In: Solomon S, Qin D, Manning M, Chen Z, Marquis M, Averyt KB, Tignor M, Miller HL (eds) Climate change 2007: The physical science basis. Contribution of Working Group I to the Fourth Assessment Report of the IPCC. Cambridge University Press, Cambridge

Christensen JH, Carter TR, Rummukainen M, Amanatidis G (2007b) Evaluating the performance and utility of regional climate models: the PRUDENCE project. Clim Chang 81:1-6. doi:10.1007/s10584-006-9211-6

Dudhia J (1989) Numerical study of convection observed during the winter monsoon experiment using a mesoscale two-dimensional model. J Atmos Sci 46:3077-3107

Gao X, Pal JS, Giorgi F (2006) Projected changes in mean and extreme precipitation over the Mediterranean Region from a high resolution double nested RCM simulation. Geophys Res Lett 33, L03706. doi:10.1029/ 2005GL024954

Gao L, Bernhardt M, Schulz K (2012) Elevation correction of ERA-Interim temperature data in complex terrain. Hydrol Earth Syst Sci 16:4661-4673. doi:10.5194/hess-16-4661-2012

Giorgi F (2006) Climate change hot spots. Geophys Res Lett 33, L08707. doi:10.1029/2006GL025734

Giorgi F, Mearns LO (1991) Approaches to the simulation of regional climate change: a review. Rev Geophys 29:191-216

Giorgi F, Hurrell J, Marinucci M, Beniston M (1997) Elevation dependency of the surface climate change signal: a model study. J Clim 10:288-296

Gómez-Navarro JJ et al (2012) What is the role of the observational dataset in the evaluation and scoring of climate models? Geophys Res Lett 39, L24701. doi:10.1029/2012GL054206

Heikkilä U, Sandvick A, Sorteberg A (2010) Dynamical downscaling of ERA-40 in complex terrain using the WRF regional climate model. Clim Dyn 37:1551-1564. doi:10.1007/s00382-010-0928-6

Herrera S et al (2012) Development and analysis of a 50 year high-resolution daily gridded precipitation dataset over Spain (Spain02). Int J Climatol 32:74-85. doi:10.1002/joc.2256

Hong S, Dudhia J, Chen S (2004) A revised approach to ice microphysical processes for the bulk parameterization of clouds and precipitation. Mon Weather Rev 132:103-132

Hong S, Noh Y, Dudhia J (2006) A new vertical diffusion package with an explicit treatment of entrainment processes. Mon Weather Rev 134:2318-2341

Iacono MJ et al (2009) Radiative forcing by long-lived greenhouse gases: calculations with the AER radiative transfer models. J Geophys Res 113, D13103. doi:10.1029/2008JD009944

Jiménez-Guerrero P et al (2013) Mean fields and interannual variability in RCM simulations over Spain: the ESCENA project. Clim Res 57:201-220. doi:10.3354/cr01165

Jorba O, Loridan T, Jiménez-Guerrero P, Baldasano JM (2008) Annual evaluation of WRF-ARW and WRFNMM meteorological simulations over Europe. 9th Annual WRF Users' Workshop. 23-27 June, 2008. Boulder, CO. USA

Kain JS (2004) The Kain-Fritsch convective parameterization: an update. J Appl Meteorol 43:170-181

Livezey RE, Chen WY (1983) Statistical field significance and its determination by Monte Carlo techniques. Mon Weather Rev 111:46-59

Marsland SJ et al (2003) The Max-Planck-Institute global ocean/sea-ice model with orthogonal curvilinear coordinates. Ocean Model 5:91-127. doi:10.1016/S1463-5003(02)00015-X

Martin A et al (2007) Sensitivities of a flash flood over Catalonia: a numerical analysis. Mon Weather Rev 135: 651-669. doi:10.1175/MWR3316.1

Martín-Vide J (1992) El Clima. Geografia General dels Països Catalans. Enciclopèdia Catalana 1:1-110, Barcelona

Mercader J, Codina B, Sairouni A, Cunillera J (2010) Results of the meteorological model WRF-ARW over Catalonia using diferent parametrizations of convection and cloud microphysics. Tethys 7:75-86. doi:10. 3369/tethys.2010.7.07

Nakićenović et al (2000) Emissions scenarios 2000-Special Report of the Intergovernmental Panel on Climate Change (SRES-IEEE). Cambridge University Press, Cambridge, RU, 570pp. Available at: http://www.ipcc. ch/ipccreports/sres/emission/index.php?idp $=0$

Nieto S, Rodríguez-Puebla C (2006) Comparison of precipitation from observed data and general circulation models over the Iberian Peninsula. J Clim 19:4254 4275

Niu GY et al (2011) The community Noah land surface model with multiparameterization options (Noah-MP): 1.Model description and evaluation with local-scale measurements. J Geophys Res 116, D12109

Randall DA et al (2007) Climate models and their evaluation. In: Solomon S, Qin D, Manning M, Chen Z, Marquis M, Averyt KB, Tignor M, Miller HL (eds) Climate change 2007: the physical science basis. Contribution of Working Group I to the Fourth Assessment Report of the IPCC. Cambridge University Press, Cambridge 
Roeckner E (2005a) IPCC MPI-ECHAM5_T63L31 MPI-OM_GR1.5L40 20C3M_all run no.1: atmosphere 6 HOUR values MPImet/MaDGermany. World Data Center for Climate, Hamburg, Germany. CERA-DB "EH5-T63L31 OM 20C3M $16 \mathrm{H} "$

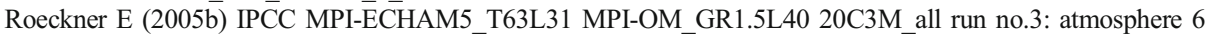
HOUR values MPImet/MaDGermany. World Data Center for Climate. Hamburg, Germany. CERA-DB "EH5-T63L31_OM_20C3M_3_6H"

Roeckner E et al (2003) The atmospheric general circulation model ECHAM5. Part I. Max-Planck Institut für Meteorologie. Report No. 349, Hamburg, Germany, 127pp

Roeckner E, Lautenschlager M, Schneider H (2006a) IPCC-AR4 MPI-ECHAM5_T63L31 MPI-OM_GR1.5L40 SRESA2 run no.1: atmosphere 6 HOUR values MPImet/MaDGermany. World Data Center for Climate, Hamburg, Germany. doi:10.1594/WDCC/EH5-T63L31_OM-GR1.5L40_A2_1_6H

Roeckner E et al (2006b) IPCC-AR4 MPI-ECHAM5 T63L31 MPI-OM_GR1.5L40 SRESA2 run no.3: atmosphere 6 HOUR values MPImet/MaDGermany. World Data Center for Climate, Hamburg. Germany. doi:10. 1594/WDCC/EH5-T63L31_OM-GR1.5L40_A2_3_6H

Roeckner E et al (2006c) IPCC-AR4 MPI-EC $\bar{C} H A \bar{M} \overline{5}$ T63L31 MPI-OM_GR1.5L40 SRESA1B run no.1: atmosphere 6 HOUR values MPImet/MaDGermany. World Data Center for Climate, Hamburg, Germany. doi:10.1594/WDCC/EH5-T63L31_OM-GR1.5L40_A1B_1_6H

Roeckner E et al (2006d) IPCC-AR $\overline{4}$ MPI-ECHAM $\overline{5}$ T63 $\bar{L} 31$ MPI-OM_GR1.5L40 SRESA1B run no.3: atmosphere 6 HOUR values MPImet/MaDGermany. World Data Center for Climate, Hamburg, Germany. doi:10.1594/WDCC/EH5-T63L31 OM-GR1.5L40 A1B 3 6H

Roeckner E et al (2006e) IPCC-AR4 MPI-ECHAM5_T63L31 MPI-OM_GR1.5L40 SRESB1 run no.1: atmosphere 6 HOUR values MPImet/MaDGermany. World Data Center for Climate, Hamburg, Germany. doi:10. 1594/WDCC/EH5-T63L31_OM-GR1.5L40_B1_1_6H

Roeckner E et al (2006f) IPCC-AR4 MPI-ECHAM-̄̄ T-63L31 MPI-OM_GR1.5L40 SRESB1 run no.3: atmosphere 6 HOUR values MPImet/MaDGermany. World Data Center for Climate, Hamburg, Germany. doi:10. 1594/WDCC/EH5-T63L31_OM-GR1.5L40_B1 3_6H

Romero R, Guijarro JA, Ramis C, Alonso S (1998a) A 30-year (1964-1993) daily rainfall data base for the Spanish mediterranean regions: first exploratory study. Int J Climatol 18:541-560

Romero R, Ramis C, Alsonso S (1998b) Performance of two cumulus convection parameterizations for two heavy precipitation events in the Western Mediterranean. Meteorol Atmos Phys 66:197-214

Rummukainen M (2010) State-of-the-art with regional climate models. WIREs Clim Chang 1:82-96

Skamarock WC, Klemp JB (2008) A time-split non hydrostatic atmospheric model for weather research and forecasting applications. J Comput Phys 227:3465-3485

SMC (2012) Butlletí Anual d'Indicadors Climàtics 2011. Servei Meteorològic de Catalunya, Barcelona, Spain, 77pp. Available at: http://bit.ly/196Z14j

Soares PMM et al (2012) WRF high resolution dynamical downscaling of ERA-Interim for Portugal. Clim Dyn 39:2497-2522. doi:10.1007/s00382-012-1315-2

Taylor KE (2001) Summarizing multiple aspects of model performance in a single diagram. J Geophys Res 106(D7):7183-7192. doi:10.1029/2000JD900719

Uppala SM et al (2005) The ERA-40 re-analysis. Q J R Meteorol Soc 131:2961-3012. doi:10.1256/qj.04.176

van der Linden P, Mitchell JFB (2009) ENSEMBLES: climate change and its impacts. Summary of research and results from the ENSEMBLES project. Met Office Hadley Centre, Exeter. Available at: http://ensembles-eu. metoffice.com/docs/Ensembles_final_report_Nov09.pdf

van Ulden AP, van Oldenborgh GJ (2006) Large-scale atmospheric circulation biases and changes in global climate model simulations and their importance for climate change in Central Europe. Atmos Chem Phys 6: 863-881. doi:10.5194/acp-6-863-2006

von Storch H, Langenberg H, Feser F (2000) A spectral nudging technique for dynamical downscaling purposes. Mon Weather Rev 128:3664-3673

Wilks DS (2006) Statistical methods in the atmospheric sciences. International geophysics series 91. Elsevier Academic Press Publications, USA, 627pp 